\title{
Efectos causados por un legislador compulsivo en el principio constitucional de seguridad jurídica. El ejemplo de las amplificadas tasas judiciales
}

\author{
Eduardo Sánchez Álvarez \\ Doctor en Derecho Procesal por la UNED
}

\begin{abstract}
SUMARIo: 1. Introducción.-2. Una imparable motorización legislativa.-3. ¿Qué es el ordenamiento jurídico en nuestros tiempos? La galopante crisis de la ley.-4. Recordatorio sobre el principio constitucional de seguridad jurídica. Contenido y alcance. 4.1. Del deber ser... 4.2. Al verdadero ser...-5. Un supuesto concreto: la regulación presente de las tasas judiciales. 5.1. Consideración general. 5.2. La regulación de las tasas judiciales desde el principio de seguridad jurídica. - 6. Idea final.
\end{abstract}

\section{INTRODUCCIÓN}

En estos tiempos convulsos, los juristas estamos perdiendo una de las que deberían suponer nuestras primordiales herramientas de trabajo: un calmado sosiego ${ }^{1}$. Si se pide al operador jurídico que sus análisis sean ponderados, certeros, afinados, suficientemente razonados desde los criterios de la Ciencia jurídica, el peor enemigo que podemos tener enfrente es la prisa, la urgencia estructuralizada, la modificación constante de nuestro objeto de estudio que nos impida llevar a buen puerto esa actividad jurídicamente racional desde una mínima tranquilidad. Y sin esos cánones, la aportación de la Dogmática jurídica se depaupera irremediablemente.

Ante la coyuntura socioeconómica que por desgracia estamos atravesando, muchos postulados jurídicos ceden o se intentan deformar para adaptarse a ese escenario en curso, buscando ser útiles elementos en la participación de su superación. Por eso, nos enfrentamos a un cuestionamiento o relativización de un buen número de conceptos jurídicos que, aunque en principio debieran hallarse anhelablemente al margen de estas interferencias manteniendo su perentoria estabilidad, por conllevar las vigas maestras sobre las que descansan las bases del Ordenamiento jurídico,

${ }^{1}$ «En tiempos de grandes inquietudes y angustias no están de más los esfuerzos de reflexión serena, que quizá contribuyan a calmar las turbulencias, al menos en el interior de quienes, por profesión y vocación, han de ejercitarse intelectualmente y no sería bueno que quedasen encadenados a la agitación de la actualidad. De quienes sean simples tributarios de lo actual e inmediato, sólo podemos esperar espasmódicas reformas legales habitualmente desprovistas de serio fundamento, cuando no disparatadas» en DE LA OLIva Santos, A, El papel del Juez en el proceso civil. Frente a la ideología, prudentia iuris, Thomson Reuters, Pamplona, 2012, pág. 14. 
también pasan a formar parte del armamento jurídico con el que se acomete la lucha contra la crisis, normando las sucesivas decisiones políticas que al efecto se van tomando.

Ahora mismo, la seguridad jurídica sufre unos rutilantes embates. El oleaje furioso del enfurecido océano normativo golpea incesante sus cimientos. Incluso institutos como el proceso, intrínsecamente insertado en el atinadamente llamado momento jurídico del Estado, bastante impermeable al oportunismo político habida cuenta de su incuestionable condición técnicojurídica, recibe estos desasosegantes impactos ${ }^{2}$. En este trabajo observamos esa tempestad agudizada por las nuevas tasas judiciales y tratamos de contrastar cuánto daño causan a la constitucionalizada seguridad jurídica.

\section{UNA IMPARABLE MOTORIZACIÓN LEGISLATIVA}

La doctrina jurídica ya ha venido advirtiendo reiteradamente en los últimos tiempos de cómo las legislaturas más cercanas cronológicamente a nosotros han ido engrosando de forma exponencial el imperio de la llamada motorización legislativa, esto es, una compulsión creadora de normas jurídicas que pasan a erigir un desaforado cúmulo, desarmónico, inaprensible, antinómico, fugaz, desordenado, elefantiásico.

Los peligros de ese diseño elegido y perseverado inatacablemente por los sucesivos legisladores son más que rotundos. Encierran en sí altos riesgos de colapso del Ordenamiento jurídico, que quedaría transformado en un agregado ininteligible de normas que pocas relaciones de conjunto podrían trabar con el resto de elementos normativos con los que, en condiciones normales, habrían de interaccionar en aras del entretejimiento de un veraz conjunto normativo.

La tozuda realidad nos demuestra que la situación presente es justamente la contraria. La inercia legislativa traza como vectores sobre los que desplazarse una ingente población normativa, una constante mutabilidad de ese universo normativizado y una técnica legislativa que no se esmera especialmente en mantener la coherencia interna de lo que debería ser un sistema, al que se desvertebra continuadamente. Sí se afana, por contra, en dotar de formulación jurídica a la más peregrina ocurrencia que en un determinado

2 «Es cierto que las ideas politicas influyen en toda clase de normas jurídicas, ya que las leyes positivas son desgraciadamente los instrumentos de que se valen los politicos para modificar las realidades sociales. Pero ello no significa en forma alguna que dichas ideas politicas puedan servir para modificar los conceptos y mucho menos la propia esencia de las instituciones jurídicas (...) Esta neutralidad del proceso respecto de las ideas políticas es particularmente estable en el ámbito del proceso civil, como lo muestran el ejemplo de las legislaciones italiana (...) y española, que han subsistido casi sin modificaciones a través de regímenes políticos totalmente opuestos» en SERRA DOMínguez, M, «Liberalización y socialización del proceso civil. Las realidades del juez en la legislación y en la realidad procesales» en Revista de Derecho Procesal Iberoamericana, no 2-3, Madrid, 1972, págs. 512-514. 
momento pueda llamar la atención del legislador haciendo caso omiso tantas veces a los propios mecanismos alumbrados dentro del Ordenamiento jurídico para llevar a término creaciones y modificaciones normativas, en ocasiones de manera drástica y, en otras, mutándolos subrepticiamente para lograr sus objetivos pareciendo que se respetan esas formalidades cuando en realidad no es así.

El legislador ya no respeta el producto que se le encarga formular: las normas jurídicas. Simplemente se sirve de ellas para que formalmente ganen coactividad sus intereses más particulares dejando de lado cualquier sesgo de generalidad o calidad técnico-jurídica. La confusión entre el momento político y el momento jurídico del Estado ha devenido absoluta, y el citado en segundo lugar se va plegando para encajar dentro del primeramente relatado. Se dice que solamente hay un Poder en el Estado y que ése es el Ejecutivo. Esa manifestación no es descabellada, y el legislador va recluyéndose en el gran cercado gubernativo que todo lo envuelve y controla ${ }^{3}$.

Más que de normas en el sentido rigurosamente jurídico de la expresión, observamos un Ordenamiento jurídico constituido por una amalgama amorfa de productos formalmente normativizados, con utilidad cuestionable, estructuralmente modificables, muchas veces meras ocurrencias de dudosa necesidad, distante a cualquier calidad técnica, erigiendo una cadena sin fin que tiene por frontispicio una decidida dispersión jurídica, un fenómeno de descodificación y desparramamiento normativo frontalmente opuesto al ideal sistemático y codificador... un bloque normativo que se convierte en un problema más de la sociedad a la que en principio sirve y regula, presidido por la oscuridad que acarrea una humanamente inexistente posibilidad de cognoscibilidad de la maraña de sus integrantes a pesar de que, naturalmente, su coactividad va a proyectarse decididamente sobre los sujetos a su vis jurídica.

Mientras, desde los poderes públicos, se proclama que hay que transmitir al exterior, en especial a los tan temidos mercados financieros de quienes parece depender en buena medida la recuperación del flujo crediticio, sensación de confiabilidad, de estabilidad, de credibilidad nacional. Bien, es compresible y compartible ese diagnóstico y la sociedad entera ha de aprestarse a colmarlo. Pero, ¿acaso un marco jurídico rector y regulador de esa sociedad que se halle en un estado de estructural mutabilidad no se opone radicalmente

3 «Esa concepción jacobina del Poder se manifiesta, en algunos Estados modernos, en una identificación del Estado como tal con uno solo de los poderes del mismo, el Ejecutivo, que ejerce un monopolio de facto sobre los otros dos poderes. Ciertamente, el Poder Ejecutivo oscurece el protagonismo del Parlamento al que controla a través de la mayoría parlamentaria que le sostiene (...) Un sistema que se funda en el control del gobierno judicial a través de la elección de sus miembros por el Parlamento exterioriza claramente lo que acabamos de exponer y las mayorías exigidas para su elección, fomentan la politización de los candidatos y, por tanto, aumenta el riesgo de una exteriorización negativa de la imagen de todo el conjunto del sistema judicial» en Chamorro GonzÁlez, J. Mª, «El gobierno de Juzgados y Tribunales» en Poder Judicial y unidad jurisdiccional en el Estado autonómico, $\mathrm{n}^{\circ}$ 90, CGPJ, Estudios de Derecho judicial, Madrid, 2006, págs. 510-511. 
a la consecución de semejante logro? El legislador no puede pedir a la sociedad que intente inspirar a las instancias que correspondan una calma, una predictibilidad de reacciones y comportamientos, cuando él mismo se afana en enrocarse sobre la antítesis de la firmeza por gracia de sus obras.

La viveza de estas afirmaciones generales nos parece inatacable. Hay principios jurídicos estructurales de nuestro Ordenamiento jurídico, con anclaje positivadamente constitucional, que son continuadamente ninguneados o lesionados por el abrasador torbellino de la creación normativa del legislador, lo que convierte a esos postulados constitucionales no en las bases de la actividad legislativa sino en apéndices secundarios y sacrificables. El momento político del Estado arrasa al jurídico cuando debería suceder justo lo contrario. Se produce una incomprensible e injustificable inversión en la pirámide de valores juridificados que conforma el Sistema jurídico estatal, pues normativa de creación en masa ladea y no respeta criterios jerárquicamente superiores dotados de plena normatividad. Tal sucede con el principio constitucional de seguridad jurídica prevenido por el art. 9.3 de la Constitución española (CE). Su sentido es antagónico con un Ordenamiento construido en torno a la aceleración de última hora, a la legislación de usar y tirar, al cambio legislativo ante la primera dificultad interpretativa que surge al aplicar una norma que, además, va a estar acrecentada por la falta de mínima reflexión al formularla, a la vista de la deficiente técnica legislativa de la que se viene haciendo uso en los últimos tiempos. La sucesión de normas es torrencial. La desistematización del Ordenamiento jurídico, una realidad incontrovertible.

En estas páginas se propone contrastar los padecimientos que sufre la seguridad jurídica como principio constitucional, su vaciado de contenido por la inercia de la desbocada compulsión legislativa. Y se busca ejemplificar esa afirmación mediante un supuesto concreto: la regulación presente de las tasas judiciales que en apenas unas semanas ya cuenta con un imponente reguero de problemas y cambios, así como con una contestación social y jurídica más que notable que, en última instancia, permite incluso dudar de la constitucionalidad de algunos aspectos de su formulación.

\section{3. ¿QUÉ ES EL ORDENAMIENTO JURÍDICO EN NUESTROS TIEMPOS? LA GALOPANTE CRISIS DE LA LEY}

Tenemos que esforzarnos en dibujar los contornos que cubre el Derecho. $\mathrm{Y}$ tal labor conduce a afirmar que el Derecho no puede resignarse a ser una suerte de realidad indeterminada. Al contrario, lo conforma un sistema de normas e instituciones que pueden rubricarse como Ordenamiento jurídico, o lo que es igual, las «normas e instituciones que configuran la organización y el funcionamiento del Estado y sus relaciones con la sociedad a la que vertebra» ${ }^{4}$.

${ }^{4}$ Murillo de la Cueva, P. L, «La independencia judicial y la ley» en Parlamento y Poder Judicial, n 106, CGPJ y Cortes de Aragón, Estudios de Derecho judicial, Madrid, 
Ahora bien, nunca nuestro Ordenamiento jurídico lo ha sido menos. El rasgo principal del Ordenamiento jurídico coetáneo puede estribar en que no lo es, por sorprendente que parezca esta proclamación. Simplemente nos hallamos ante un monstruoso y amorfo agregado de normas jurídicas totalmente inabarcable, incognoscible, ayuno de cualquier pretensión de plenitud o coherencia interna. Visualizamos una maraña, una selva impenetrable de productos jurídicos de diversa naturaleza, con una calidad tantas veces ínfima, que arrumba pretensiones que debieran hallarse a pleno rendimiento, más allá de su solemne aseguramiento formal en los textos jurídicos jerárquicamente superiores. Cualquier acercamiento al Ordenamiento jurídico constata su carencia de armonía, y ensalza su caótica dispersión.

Certeramente, concluye LóPEZ JiMÉNEZ que «el siglo XIX fue el de la codificación, el siglo XX el de la descodificación $»^{5}$. Los comienzos del siglo XXI ratifican esta afirmación, pulverizando ese empeño histórico y los monumentos legislativos erigidos con tanto esfuerzo ${ }^{6}$. Nuestros códigos reflejan

2006, pág. 77.

5 LÓPEZ JIMÉNEZ, J. M ${ }^{\text {a }}$, «Algún criterio para mitigar la hiperabundancia normativa: STS (Sala primera) de 23 de febrero de 2009», Diario La Ley, $\mathrm{n}^{\circ} 7212$, de 7 de julio de 2009. Como apunta DE RAMÓn Fors, considerando «la incesante y caudalosa producción normativa que nos asfixia, y que la función unificadora del Tribunal Supremo parece estar condenada a ir diluyéndose, tanto por el desmesurado volumen de trabajo que tiene que afrontar dicho organismo como por la aparición de otros Tribunales que asumen esa misma competencia. Todo ello incrementa la complejidad del Ordenamiento jurídico y propicia su falta de armonía (...) Los juristas no somos conscientes de hasta qué punto el Derecho vigente se está convirtiendo en algo cuyo conocimiento es inaccesible para el ciudadano normal; e incluso los juristas se ven obligados a especializarse y, lo que es peor, aunque lo intenten no consiguen penetrar en los arcanos de otras materias que no sean las que habitualmente estudian» en DE RAMÓN Fors, I., «Sobre la necesidad de perfeccionar el Ordenamiento jurídico» en Diario La Ley, nº 7152, Ed. La Ley, Madrid, de 8 de abril de 2009.

${ }^{6}$ Como atinadamente argumenta PALMA FERNÁNDEZ, «frente a una aparente interpretación pragmática (codificar como simple acto de reunir y ordenar normas) resulta que codificar es mucho más que agrupar normas en un código. El sentido final de la codificación (...) tiene mucho que ver con la superación de una sociedad (...) y el triunfo de una nueva dimensión del poder público, de ineludible matiz constitucional, confiriendo al Estado la misión trascendental de proteger y sancionar los derechos individuales de cada uno (...) Los mismos paradigmas de la Codificación empiezan a definirse en relación con el concepto de Constitución (...) en su condición de norma normarum (...) Si codificar supone elaborar un orden normativo sobre una materia con arreglo a un método, nada puede haber más perturbador que la continua llegada y salida de normas de ese código. La aspiración de exhaustividad de todo texto codificado, cuyo objeto último es la certeza del Derecho y la consecución de la seguridad jurídica respecto a la norma aplicable, sufre infinitamente desde el momento en que pierde vigencia parte de su contenido por la aparición de una nueva norma o por la eliminación de una de las antiguas, recogidas en él (...) La inestabilidad de las normas (...) y la abundante degradación normativa (...) son otras razones que contribuyen a la confusión y dificultad que ofrece el Ordenamiento jurídico (...) actual» en PALma FernÁNDEZ, J. L., «La codificación en España. De los turdetanos a Internet» en Diario La Ley, n 7552, Ed. La Ley, Madrid, de 21 de enero de 2011. 
y subliman siglos de sabiduría jurídica que han resistido perfectamente a una multitud de cambios políticos, sociológicos, económicos... durante su dilatada vigencia. Proceder a una descodificación, abundante y de vida temporal intrínsecamente corta, genera el efecto contrario: inseguridad, inestabilidad, desigualdad e injusticia. El ideal codificador se sustenta en una concepción del Derecho como un orden lógico y racional. La dispersión normativa se funda, por contra, en una extenuante labor de concreción aplicativa del Derecho en cuyo honor se sacrifica esa formulación normativa lógica y racional. Se opta por crear más legislación en vez de aplicar correctamente la previamente promulgada sirviéndose del instrumental interpretativo que ya existe igualmente normativizado (sin más, art. 3.1 del Código Civil).

Nuestro ritmo de vida es acelerado, atropellado. Y esta circunstancia tiene fiel reflejo en lo que atañe a la multiplicación exponencial de normas jurídicas provenientes de una catarata de centros creadores. El Ordenamiento debe aspirar a la plenitud para serlo, articulándose también la provisión de las reglas de autointegración interna que la asevere incontrovertidamente junto a las que permitan la selección de la norma integrante aplicable a un supuesto que la praxis active. Digamos ilustrativamente que ZARRALUQUI numeraba en 344.554 las normas jurídicas vigentes en España allá a finales de $2005^{7}$. Es humanamente imposible conocer todo ese universo normativizado ${ }^{8}$. Y deviene esperable que existan múltiples defectos de formulación técnica y distonías entre esa muchedumbre jurídica.

Se legisla masiva y masificadamente. Se redactan leyes y más leyes, normas reglamentarias por millares, artefactos jurídicos de discutible naturaleza en sumas incontables... destrozando en una catastrófica inundación a las sistematizadas fuentes tradicionales del Derecho. Se obvia que el proceso legislativo exige perentoriamente tranquilidad: una vez regulada cualquier eventualidad fáctica hay que dejar transcurrir tiempo para que las normas en cuestión se aposenten, maduren y den sus frutos.

La ley también se ha convertido en un instrumento que pretende ser la solución filosofal para solventar cualquier problema que la práctica haga surgir, olvidando que la pura letra legal publicada en el soporte correspondiente no suele operar esa demiúrgica taumaturgia sin más. Al contrario, cualquier ley, por perfecta que se formule técnicamente, precisa indefecti-

7 Zarraluqui SÁnchez-Eznarrinaga, L., «El Ordenamiento jurídico bajo camuflaje» en Revista del Consejo General de la Abogacía española, n 49, Madrid, 2008.

${ }^{8}$ Con una solera histórica centeraria, demostrando que la cuestión ya viene de lejos y se ha agudizado todavía mucho más en los tiempos coetáneos a nosotros, «las leyes de todo Estado civilizado ocupan bibliotecas enteras y apenas se encuentra quien conozca superficialmente todo el sistema jurídico de su país. La presunción de que todo ciudadano conoce todas las leyes es la más ridícula de las invenciones, y los perjuicios que el legislador ocasiona por la ignorancia de las leyes son una injusticia palmaria que (...) hiere especialmente a las clases inferiores de la sociedad» en Menger, A., El Derecho Civil y los pobres, Victoriano Suárez, Madrid, 1898, pág. 405. 
blemente de recursos y medidas que permitan e implementen su veraz eficacia y eficiencia.

Aunque la ley permanezca ocupando un lugar preeminente en el Ordenamiento jurídico, exteriorizando postulados como su posición basal del Estado de Derecho, o que sin su concurso normativo no sea exigible una coactiva obediencia o una afectación de derechos subjetivos, o la tipificación de conductas delictivas o sancionadoras... la gradual desvalorización del valor-ley es absolutamente incuestionable. Y justamente la fugacidad de las leyes es un gran indicio de la decadencia legal. Como remedio a esta situación, la doctrina ha apuntado una conveniente revalorización de la Constitución como garantía superior a la ley -contando con una más sólida y normativizada estabilidad- convertida, además, en parámetro de validez de aquélla: se trata de insertar una Norma suprema rígida y ordenadora de la subordinada ley, que acotaría la actuación del legislador y la supeditaría a los principios jurídicamente vinculantes que se amarraran al texto constitucional. El inconveniente, lógicamente, radicaría en la latente insuficiencia de la Norma constitucional para regular y proteger con la debida entidad por sí sola el conjunto de derechos ciudadanos?

El Derecho se ha decantado por una visión primordialmente legislativa. Su correlato pasa a ser la inflación normativa quien, a su vez, gesta la crisis de la ley que cuenta con uno de sus rasgos señeros en la escasa calidad técnica de esas normas. La certidumbre en el momento aplicativo del Derecho, sobre ese prius, se vuelve un imposible al quedar envuelta en una multiplicidad de titubeantes elucubraciones habilitadas resueltamente por el per se patológico Ordenamiento jurídico. La proliferación legislativa demuestra tanto la decadencia del Derecho cuanto de la ley como garantía. A mayor número de leyes, más desvalorización del valor-ley que, simultáneamente, nutre una voraz demanda de más legislación que, a su vez, vuelve a provocar igual efecto desvalorizante.

Desde luego, aunque la actitud del legislador permita albergar remotas esperanzas en este sentido, se antojaría imprescindible articular con máxima urgencia una racionalización del Ordenamiento jurídico: adelgazamiento de normativa inútil o redundante, simplificación legislativa, retorno al imperio de la sana idea del sistemático fenómeno codificador que huye de una insufrible dispersión normativa, reforzamiento de la relevancia de la doctrina jurisprudencial, fusión de textos normativos que tienen igual (y a veces contradictorio) objeto de regulación... Justamente en un devastador tsunami normativo, la tabla de salvación para sobrevivir a este desastre estriba, en nuestra

${ }^{9}$ «En materia de derechos resulta aún más dificil trazar una línea entre constitucionalidad y legalidad ya que Constitución y ley colaboran a la hora de determinar el contenido y alcance de los derechos, siempre bajo la supremacía de la primera. Y asi lo ha reconocido el propio Tribunal Constitucional (STC 50/1984, por ejemplo)» en PÉREZ Tremps, P., «Tribunal Constitucional, Juez ordinario y una deuda pendiente del legislador» en La reforma del recurso de amparo, Madrid, 2004. 
opinión, en la vuelta a la siempre segura mansión histórica del Derecho, a su fortaleza, a sus grandes e impertérritos principios que, por cierto, en gran medida habitan en la Constitución dotados de fuerza normativa directa ${ }^{10}$.

Sin embargo, la misma proliferación legislativa está provocando lesivos efectos en estos principios jurídicos, entre los que se halla la seguridad jurídica, que se ven abiertamente resentidos en su virtualidad. La compulsión legislativa deshilacha esos genéricos principios en aras de la creación de subprincipios específicos en cada área del Derecho, mutados en miniprincipios sectoriales que más que probablemente poco tengan que ver con sus homólogos en otras ramas jurídicas, lo que descompone y cuartea principios globales y sólidos en otros pequeños y debilitados que, a la postre, son inconexos e incoherentes entre sí, cuando no dejan de serlo por suponer meramente recomendaciones técnicas que deberían hallarse ayunas de la catalogación de principio (por definición los principios han de ser pocos: «cuando todo son principios, nada es principio» ${ }^{11}$ ).

Aún hay factores que agravan tan penosa coyuntura: exacerbar procesos de continuada producción normativa, irreflexiva e irresponsable, puede generar expectativas que, de inmediato, vista la imposibilidad presente de acompañarlas de las necesarias dotaciones económicas ante la escasez de recursos públicos reinante, provocarán irremediable y expandida frustración social. El ámbito de la tan esperada Ley 39/2006, de 14 de diciembre, de Promoción de la Autonomía personal y Atención a las Personas en situación de Dependencia, Boletín Oficial del Estado (BOE), 15 de diciembre de 2006, $\mathrm{n}^{\mathrm{o}} 299$, puede ser un perfecto ejemplo de lo que se expone.

La crisis del Ordenamiento jurídico, su postrante degradación, sus cambios continuados que reflejan crudamente la ausencia de un esquema creíble para elaborar una línea legislativa, la falta de un proyecto que, simultáneamente, sustente paradigmas legislativos no fundados en la necesidad inmediata o en la ocurrencia... quiebran su labor histórica, la misión que motivó su formulación pese a que continúa presente en la actualidad, y lo transforma en un simple atajo que únicamente condiciona y pervierte la necesaria estructura interna que, a modo de armazón, ha de sujetarlo para evitar precisamente su derrumbe.

Pero la crisis de la ley en cuanto elemento neurálgico del Ordenamiento jurídico se propulsa sobre la propia ordenación social. La ley pierde legitimidad frente a la sociedad de la que nace y a cuya normación se dirige, dejándose por el camino los fines que, en principio, le son connaturalmente propios. La ley va abandonando su intrínseca meta normativa a favor de otra más inmediata, resultadista, momentánea, inclinada hacia lo sociológico o político, de resignada llevanza de las cuestiones surgidas, incluso por inacción previa del legislador que no se anticipa a los problemas que van manifestándose y úni-

${ }^{10}$ Cfr. López Jiménez, J. Ma, «Algún criterio para mitigar la hiperabundancia normativa: STS (Sala primera) de 23 de febrero de 2009», Diario La Ley, no 7212, Ob. Cit.

11 De la Oliva Santos, A, El papel del Juez en el proceso civil. Frente a la ideología, prudentia iuris, Ob. Cit., pág. 18. 
camente se acometen cuando se descontrolan totalmente (una burbuja inmobiliaria, excesos en el sistema bancario, una crisis en ciernes que se niega...).

Entonces, ¿acaso es sencillo, de entre todo ese conjunto con tintes de universo de normas saber a ciencia cierta cuál es la aplicable, cuál se halla en vigor, cuál ostenta aplicación preferente, con cuáles ha de completarse alguna de ellas para conjuntar armoniosamente las competencias legislativas de cada sujeto con potestades en la materia? ¿No aparecerá alguna disposición que derogue parcialmente la que parecía la adecuada al caso surgido, o que derogue lo derogado? ¿Parece apropiada la supernormación de un supuesto hasta su insuperable y estrambótica saturación, mientras en otro más o menos cercano ni siquiera parezca encontrarse norma a la que acudir?

Una injustificada producción normativa aluvial destroza una necesidad olvidada: la perentoria perfección del Sistema jurídico, la reducción a la mínima expresión de las incertezas que albergue. La coherencia del Ordenamiento enlaza indiscutiblemente con la calidad jurídica, y ésta es una absoluta quimera si no resulta sencillo el conocimiento de las normas que están vigentes, cuál de ellas debe prevalecer en caso de conflicto internormativo... ¿Qué resultado de calidad podemos obtener si ni tan siquiera existe respeto al texto legislativo por parte del legislador? ¿No es del todo cierto que se mezclan sin ninguna justificación técnica normas heterogéneas en leyes de acompañamiento a las presupuestarias o en disposiciones adicionales con decenas de folios, o se denomina a las leyes con nombres que no se corresponden con su posterior contenido? ${ }^{12}$

Si el Profesor García de EnTERría alumbró el sintagma «Estado de Justicia» ${ }^{13}$ para expresar la situación en la que la totalidad de los poderes e instancias públicas quedan sujetas firmemente ya no sólo a la legalidad, sino a la fiscalización y escrutinio judicial sin esconces, no es posible que, acto seguido, las herramientas de las que la Administración de Justicia se servirá primordialmente para la culminación de ese menester, las normas jurídicas,

12 «La ley ya no es sólo garantía de libertad sino instrumento de transformación e integración, como se comprueba en la intervención económica y en la regulación de la actividad prestacional (...) Surge una regulación heterogénea, fragmentada, sectorial en la que lo problemático no es el desorden, la contingencia, sino sobre todo la carencia de un orden compartido, el criterio guía de producción legislativa que sea capaz de aportar orden al conflicto. Pero además de esta consideración de orden general, la resultante normativa de regulación de la sociedad fragmentada es susceptible de una crítica técnica porque se constata una triple característica: la proliferación de leyes, la baja calidad técnica de las leyes y el desorden en las relaciones entre las fuentes del Derecho» en GARCía Herrera, M. A. y López Basaguren, A., «Constitución y Poder Judicial: la incompleta realización del Poder Judicial», en Poder Judicial y unidad jurisdiccional en el Estado autonómico, no 90, Ob. Cit., pág. 166.

${ }^{13}$ García de Enterría, E., «La lucha contra las inmunidades del poder en el Derecho Administrativo (poderes discrecionales, poderes de gobierno, poderes normativos)» en Revista de Administración Pública, n 38, Madrid, 1962. 
se conviertan en un problema en sí mismas, disfuncionales e inválidas materialmente ${ }^{14}$.

\section{RECORDATORIO SOBRE EL PRINCIPIO CONSTITUCIONAL DE SEGURIDAD JURÍDICA. CONTENIDO Y ALCANCE}

$\mathrm{Al}$ abordar brevemente un análisis genérico del principio de seguridad jurídica, dotado ex art. 9.3 CE de resaltada naturaleza constitucional, creemos absolutamente imprescindible disociar dos aspectos apegados al mismo. $\mathrm{Y}$ es que una cosa es qué debería comprender y otra bien diferente qué es lo que realmente implica en la práctica. La dicotomía ser/deber ser encaja a la perfección al proyectarla sobre este principio jurídico-constitucional. Si la doctrina acuñó el concepto mutación constitucional para definir aquellos supuestos en los que, sin modificarse la littera constitutionis, otras vías que no son su reforma por los mecanismos previamente establecidos al efecto proceden de esa despojante manera -transformando su contenido-, muy probablemente el principio de seguridad jurídica refleje con luminosidad esta eventualidad.

\subsection{Del deber ser...}

El Diccionario de la Real Academia de la Lengua nos aporta la siguiente definición del concepto seguridad jurídica: «cualidad del Ordenamiento jurídico que implica certeza de sus normas y, consiguientemente, la previsibilidad de su aplicación».

Se leía en la Memoria 1992 del Consejo de Estado que «la seguridad jurídica garantizada en el art. 9.3 CE significa que todos, tanto los poderes públicos como los ciudadanos, sepan a qué atenerse, lo cual supone por un lado un conocimiento cierto de las leyes vigentes $y$, por otro, una cierta estabilidad de las normas y de las situaciones que en ella se definen. Esas dos circunstancias, certeza y estabilidad, deben coexistir en un Estado de Derecho». Transcribimos ese párrafo como un exponente diáfano y propedéutico que resume atinadamente lo que cabe esperar que conforme materialmente los confines constitucionales del principio de seguridad jurídica: cognoscibilidad de la normativa vigente, cumplimiento de unos estándares técnicos de

14 «Solo la buena técnica normativa en la elaboración de disposiciones puede culminar en buenos textos legales o reglamentarios. La técnica normativa depurada debe ser una política pública intemporal (...) Para mejorar el sistema de producción de normas (...) es preciso que la regulación no se reduzca a un mero acto de poder, sino que sea el resultado -como querían los ilustrados-de una voluntad alumbrada por la razón (...) En definitiva, el futuro de las normas queda siempre y en gran medida condicionado por la corrección y calidad del proceso de su elaboración, más allá del mero acto positivo de su puesta en vigor» en Palma Fernández, J. L., «La codificación en España. De los turdetanos a Internet» en Diario La Ley, $\mathrm{n}^{\circ}$ 7552, Ob. Cit. 
elaboración normativa ${ }^{15}$ y mínima estabilidad de esos elementos normativos dentro del Ordenamiento jurídico. De otra forma, ha de acoger en su seno la publicidad, la formalidad y la estabilidad ${ }^{16}$. La seguridad jurídica coadyuva de manera decisiva a la coherencia interna del Ordenamiento jurídico, que no debe proclamarse sin más sino ser objeto de una constante preocupación para su efectiva realización.

Más sucintamente, el Tribunal Constitucional (TC) ha señalado que la seguridad jurídica es una «suma de certeza y legalidad, jerarquía y publicidad normativa, irretroactividad de lo no favorable, interdicción de la arbitrariedad...» (tempranera STC 27/1981, de 20 de julio). Entonces, el legislador «debe perseguir la claridad y no la confusión normativa, debe procurar que acerca de la materia sobre la que legisla sepan los operadores jurídicos y los ciudadanos a qué atenerse (...) y no provocar juegos y relaciones entre normas como consecuencia de las cuales se produzcan perplejidades» (SSTC 46/1990, de 15 de marzo, y 146/1993, de 29 de abril). No en vano, «en la seguridad jurídica subyace la paz social» ${ }^{17}$. Así es, la seguridad jurídica se relaciona con el conocimiento del Derecho y con su mínima estabilidad, per-

15 Con detalle, Rodríguez-Arana Muñoz, J., «Principio de seguridad jurídica y técnica normativa» en Repertorio Aranzadi del Tribunal Constitucional, $\mathrm{n}^{\circ}$ 4, Pamplona, 2007. Apunta el autor que «en un Estado de Derecho las normas jurídicas se confeccionan para que se apliquen. Han de ser claras en lo que atiende a su rúbrica, a su objeto, a sus efectos y a sus destinatarios. Han de ser lo más completas posibles, lo más concretas posibles y lo más concisas que se pueda. Han de estar redactadas según los más elementales cánones de producción de normas. Es decir, han de recoger en la medida de lo posible los patrones, las reglas propias de la mejor técnica normativa. Y la mejor técnica normativa es aquélla en la que más resplandece el principio de seguridad jurídica y sus corolarios necesarios: buena fe o confianza legítima entre otros (...) El principio de seguridad jurídica exige que las normas sean claras, precisamente para que los ciudadanos sepan a qué atenerse. Cuando se fomenta la confusión, cuando se oscurece el régimen jurídico deliberadamente o se incluyen en la parte final de la norma disposiciones más bien propias del título preliminar o del preámbulo, de alguna manera se está afectando negativamente al criterio jurídico de la seguridad jurídica, medida que nos da la intensidad y autenticidad del Estado de Derecho en cada país, en cada sistema jurídico (...) La seguridad jurídica y la certeza de las normas son dos parámetros básicos del Estado de Derecho (...) La realidad es que el rigor y la calidad de las normas brillan por su ausencia».

${ }^{16} \mathrm{El} \mathrm{TC}$ «no ha dejado de advertir sobre los riesgos de ciertas prácticas legislativas potencialmente inconstitucionales por inadecuadas al sistema de fuentes configurado en la Constitución. Así lo hizo respecto de la reproducción por Ley de preceptos constitucionales (...), en otros casos en los que Leyes autonómicas reproducían normas incluidas en la legislación básica del Estado (...) o, incluso, cuando por Ley ordinaria se reiteraban preceptos contenidos en una Ley Orgánica; prácticas todas ellas que pueden mover a la confusión normativa y conducir a la inconstitucionalidad derivada de la norma, como ocurre en aquellos supuestos en los que el precepto reproducido pierde su vigencia o es modificado, manteniéndose vigente, sin embargo, el que lo reproducía» en STC 150/1998, de 2 de julio, $\mathrm{FJ}^{\circ}$.

${ }^{17}$ Guasp Delgado, J., Derecho, Gráficas Hergon, Madrid, 1971. 
misiva para dotar a la ciudadanía de unas razonables certezas de futuro y planificación vital ${ }^{18}$.

Lógicamente, la $\mathrm{CE}$ ha de interpretarse sistemáticamente. Todos los principios prevenidos por el art. 9.3 CE, a pesar de que nos centremos en uno de ellos, no son compartimentos estanco. Cada uno cobra veraz valor relacionándose con los demás (una vez más, visión de conjunto, sistémica e interrelacionada), teleológicamente orientados para promover y aseverar los valores del art. 1.1 CE que, a su vez, propugna nuclearmente el Estado social y democrático de Derecho (cfr. STC 99/1987, de 11 de junio). Singularmente, la seguridad jurídica se engarza con el principio de reserva de ley y, lato sensu, con la legalidad, proscribiendo fórmulas próximas a la arbitrariedad (vid. STC 71/1982, de 30 de noviembre). Ahora bien, el Tribunal Supremo (TS) ha llegado a bosquejar que el principio de seguridad jurídica se erige en una suerte de suma de todos los que se acogen en el art. 9.3 CE, en un equilibrio tal que permita promover dentro del orden jurídico, en libertad, tanto la justicia como la igualdad (cfr. STS de 26 de febrero de 1991, Ref. Aranzadi n 1600).

Bajo este enfoque, a la par, se fortifica una idea que a nuestro entender ha de resultar clave para apuntalar la visión sistémica del Ordenamiento jurídico: tener siempre presente la superioridad de los grandes principios $\mathbf{y}$ valores jurídicos - entre los que, obviamente, se halla la seguridad jurídicasobre las normas concretas e intrínsecamente contingentes. La colocación constitucional de este principio no es puramente decorativa, claro está. El art. 9.3 CE sirve para dotar de cimientos sólidos y con vocación de perentoria permanencia a un marco en el que la modificación normativa es en muchas ocasiones inevitable, en pos de la precisa mejora y el imprescindible progreso social que impide ipso facto la inmutabilidad normativa, contrabalanceando excesos dañinos a la propia subsistencia del Ordenamiento jurídico.

Pero ese vector debe caminar contrapesado para abortar excesos endógenamente lesivos para su teleología. Y ese atemperativo contravector radica en principios como la seguridad jurídica. Según leemos en la STC 208/1988, de 10 de noviembre, «la seguridad jurídica no exige la petrificación del Ordenamiento, pero sí el respeto a las garantías enunciadas explícitamente como tales», so pena de probable quebranto de los compromisos que el Estado ha asumido previamente. Ha de buscarse el lógico equilibrio entre la idea de progreso (que se servirá de los correspondientes cambios normativos para su avance juridificado) y seguridad jurídica (en cuanto correctivo a sus desmanes que permita el mantenimiento de un marco estable, con sostenedores rasgos perennes a cuyo cobijo se produzcan esas modificaciones y progresos). Ante el potencial conflicto entre seguridad jurídica y legalidad en la actuación administrativa, el TS ha estimado en ocasiones prioritario cumpli-

${ }^{18}$ In extenso, vid. Pérez LuÑo, A. E., La seguridad jurídica, Ariel Derecho, Barcelona, 1991. 
mentar a la primeramente referenciada con base, a su vez, en el principio de confianza cuando el obrar de la Administración «y la apariencia de legalidad de su actuación han movido la voluntad del administrado a realizar determinados actos e inversiones (...) que después no concuerdan con las verdaderas consecuencias de los actos que finalmente produce la Administración, máxime cuando esa apariencia de legalidad indujo a confusión al interesado, causándole unos daños que no tiene por qué soportar jurídicamente» (SSTS de 8 de junio de 1990 y 17 de febrero de 1997). En resumen, el principio constitucional de seguridad jurídica no es ni puede ser absoluto, pues en ese caso se produciría una petrificación del Ordenamiento, pero sí debe dotarle de una perentoria estabilidad que permita cualificarlo como tal y no como un estructuralizado agregado de mutantes normas jurídicas.

En fin, si en un sistema jurídico como el nuestro, edificado bajo el recio imperio del Estado de Derecho y el principio de legalidad, las transformaciones en las dispares posiciones jurídicas que se producen se canaliza mediante cambios legislativos o instrumentos predeterminados en las normas jurídicas que lo integran, es en esa parcela donde la garantía de estabilidad engarzada al principio de seguridad jurídica ha de guardar todo su potencial con subrayada preferencia y en conjunción con el momento aplicativo del Derecho.

En otra perspectiva concurrente, se apunta que la seguridad jurídica también implica que las normas y actos jurídicos deban revestir una determinada forma y hayan sido elaborados siguiendo una manera prefijada. Sin perjuicio de que un exacerbado formalismo acarree efectos negativos sobre la agilidad del tráfico jurídico, económico y social; su ausencia, al menos en unos mínimos suficientemente robustecidos, conlleva lesión a ese principio constitucional por cuanto carecerían del necesario y cualificante plus de validez que los distinga de una pura manifestación externa del acto o norma jurídica en liza, permitiendo el conocimiento de que los mismos se han producido por el órgano o la persona competente, que su voluntad se ha expresado de forma adecuada, etc.

Así, corroboramos que el Ordenamiento jurídico no solamente ha de comprender mutables normas, sino también otro tipo de creaciones o realidades jurídicas. De ahí que la seguridad jurídica deba proporcionar su sombra protectora de certeza a todo el Sistema, hacerlo cierto en un sentido propio y gramatical del término, transformándolo en un totum indubitado y previsible, cognoscible y verdadero. El Derecho, entendido como sistema que supera con creces los elementos puramente normativos que comprende, necesita para serlo dotarse de los rasgos de certeza, seguridad, predictibilidad... envolviéndose en un eminente impulso que tenga por frontispicio erigir un conjunto inequívoco, «de tal modo que podamos ajustar nuestra conducta a sus dictados sin temor a equivocarnos, a obrar mal, o a recibir una sanción ${ }^{19}$.

${ }^{19}$ Amorós Dorda, F. J., «Seguridad jurídica» en SOCINFO, Madrid, 2012. 
Por otro lado, sin seguridad jurídica no puede lograrse una verosímil situación de justicia material, erigida en un valor superior del Ordenamiento a la vista del art. 1.1 CE. El Derecho no debe cejar en su empeño de lograr con su normación, incluyendo como instrumento reparador a la normativa procesal con la que impetrar la solución de conflictos ante la Jurisdicción estatal, la realización de esa justicia material ${ }^{20}$. El Derecho precisa justificar si es capaz de realizar la justicia y el restante elenco de factores que conectan con ella. La justicia se erigiría en un valor jerárquicamente superior, incluso respecto a la seguridad jurídica. Sin embargo, la seguridad jurídica actúa a modo de prius respecto a la justicia: no se alcanza la segunda sin aseverar la primera. No considerar la seguridad jurídica para lograr aisladamente la justicia acarrea caos, incoherencia, desorden, casuismo y arbitrariedad. Una veraz Justicia (con mayúsculas, para toda la sociedad, para todas las personas como expresa el art. 24.1 CE) es inaccesible sin una solvente seguridad jurídica que la apoye. Las normas que se establezcan han de ser intrínsecamente justas para la generalidad abstracta de casos y supuestos presentables bajo amenaza de no constituir verdadero Derecho. El Derecho tiene que ser conocido, generando previsibilidad y aplicación mínimamente homogénea de sus prevenciones. De no ser así, no podrá acceder a esa condición ni, por supuesto, proyectar justicia material.

\subsection{Al verdadero ser...}

Así las cosas, la seguridad jurídica, en su doble faz comprensiva de la certidumbre sobre la pauta de comportamiento socialmente admitido y previsibilidad de las consecuencias en caso de anormalidad o conducta fuera de la norma ${ }^{21}$, sufre atropellada por ese mastodonte normativo. Ciertamente,

20 «Una de las motivaciones radicales que impulsa al hombre a establecer reglas de Derecho es la urgencia de crear un orden cierto (en las relaciones sociales más importantes) y de seguro cumplimiento (...) Aun cuando el Derecho está abocado a la realización de valores de rango superior (...) debe ante todo y previamente crear una situación de relativa seguridad (...) Además (...) exige que ese orden cierto y seguro sea justo, favorecedor del bien común» en Recansens Siches, L., Filosofía del Derecho, Porrúa, Méjico, 1961, pág. 618.

${ }_{21}$ Cfr. García SÁnchez, J. A., «La prevención de los litigios» en La sociedad litigio$s a$, Cuadernos de Derecho judicial, CGPJ, Madrid, 2007, págs. 247 y ss. Resalta el autor que la seguridad jurídica «abarca una faceta pública o constitucional, relacionada con el origen y ejercicio del poder y centrada en los límites de ese poder, esencialmente los derechos humanos, entre ellos los procesales y penales (...) y otra faceta jurídico-privada constituida esencialmente por los mecanismos, técnicas y resortes que transmiten al ciudadano la certidumbre sobre la ley aplicable y la previsibilidad o predictibilidad en su aplicación (...) Y también es sabido que estos principios de certidumbre y predictibilidad son aplicables no sólo al ámbito de relaciones de los ciudadanos con el poder constituido sino también al de los ciudadanos entre sí, lo que se ha denominado seguridad jurídicoprivada o contractual en sus facetas estática y dinámica, pues a ambas se extiende la aspiración de los ciudadanos de obtener seguridad jurídica (...) Para contribuir a la seguridad jurídica y mantenerse en el ámbito de una previsibilidad racional, los Jueces 
parece gozar de lozana salud a la vista del tenor del art. 9.3 CE, pero en cuanto se la observa con un pequeño detenimiento se comprueba su galopante enfermedad ${ }^{22}$. Sabido es que los contornos formales de este principio constitucional no siempre van a resultar inequívocamente nítidos, pero sí es incontrovertido que su núcleo habita en el suministro de certeza acerca de cuál es en cada momento el Derecho, así como lo que será con sólida previsibilidad en el futuro. De esa manera, se permitirá a cada cual ordenar su actitud jurídica con conocimiento de la calificación jurídica que ante cada supuesto de hecho recibirá del Ordenamiento, de tal modo que afecta tanto a las normas en abstracto tomadas como a los actos de particulares y poderes públicos.

están obligados a hacer uso de la que algunos han llamado "creatividad intersticial" que les permite leer, en los poros de la propia ley que aplican, no ya criterios subjetivos, siempre rechazables, pero si los principios superiores del Ordenamiento para interpretarla y hacerla equitativa».

22 A mayor abundamiento, vid. GonzÁlez Fernández, J. J., «Una aproximación a los principios de seguridad jurídica, buena fe y protección de la confianza legítima en Derecho Administrativo» en Noticias jurídicas, abril de 2005. «La creciente complejidad del Ordenamiento jurídico, la escasa calidad de una legislación que sigue estando motorizada, la aceleración de los cambios sociales en un contexto globalizado y en permanente transformación, mantienen al problema de la indeterminación o incertidumbre del Derecho entre las preocupaciones más destacadas de los operadores jurídicos (...) Se ha consagrado una concepción legislativa del Derecho que provoca una inflación de reglas y, al mismo tiempo, da carta de naturaleza a la crisis de la ley. Esta inflación se asocia, además, a la escasa calidad técnica de las normas. Los cambios permanentes de las normas, el flujo interminable de decisiones, provoca también una crisis de la información jurídica, que precipita en las tinieblas al Ordenamiento jurídico (...) Una inflación de leyes desbocadas (...) que dificilmente pueden abarcar los distintos supuestos conflictivos y tienen que ser aplicadas en un contexto marcado por la diversidad cultural (...) Una legislación deficiente y en permanente cambio unida a la coexistencia de diversos contextos de sentido y valor, fruto de la diversidad cultural y formativa, convierten en tarea hercúlea la búsqueda de factores de previsibilidad o certidumbre en la aplicación del Derecho». No es marginable sentar que «la seguridad jurídica es un valor económico. Las resoluciones judiciales contradictorias profundizan el déficit de legitimidad que la Justicia sufre en la opinión pública y que está en buena medida provocada por factores totalmente ajenos al Sistema judicial, como son los factores estructurales (la creciente opacidad del Ordenamiento jurídico, debido a la inflación legislativa y a la escasa calidad de la legislación), los axiológicos (la diversidad de culturas juridicas y valores característica de las sociedades contemporáneas) y los organizativos (ámbito de la Jurisdicción, régimen de recursos y planta judicial) (...) Situados en un marco tan plural y complejo (...) se comprende que los derechos fundamentales, como los principios generales del Derecho, operen como el principal sustrato de certidumbre del Sistema juridico (...) El sentido último de los derechos fundamentales no consiste, en definitiva, sino en no dejar en manos ni siquiera de la mayoría parlamentaria la decisión sobre las posiciones esenciales del individuo. Los derechos fundamentales presentan de este modo una doble dimensión. Confieren derechos subjetivos pero, al mismo tiempo, representan un cuadro de valores objetivo que sirve de directriz a la legislación, la administración y la justicia», REMÓN PEÑALVER, J., «La lucha por la seguridad jurídica» en Diario La Ley, n 6642, de 1 de febrero de 2007. 
Analizado desde el enfoque de la técnica legislativa, el principio de seguridad jurídica impone rigurosidad, claridad, precisión que engendre que las leyes formuladas permitan estabilidad en las situaciones jurídicas y su modificabilidad únicamente de la forma predeterminada en esas manifestaciones normativas. A la inversa, la inseguridad jurídica enlaza con la mala técnica legislativa que acarrea inestabilidad, al provenir de normas mal construidas, cambiantes; reflejo in abstracto de la contrastable pendularidad del sistema político, del titubeo administrativo, de su dudosa discrecionalidad y, judicialmente, de una tutela ineficaz.

Evidentemente, la desmesura e hiperutilización coronan el ejercicio de la función legislativa, y no digamos el de la actividad reglamentaria ${ }^{23}$. De paso, semejante hiperabundancia de normas jurídicas exterioriza a un Estado que tiene una tendencia latente a sustraerse de las regulaciones previamente establecidas por el Derecho Público para proceder a una intromisiva ampliación cada vez menos disimulada sobre la vida de sus ciudadanos, con un intervencionismo que arrincona la labor vicarial que debería desarrollar, esto es, estar al servicio de los particulares. Una auténtica reunión de desmanes legislativos ${ }^{24}$.

Como se comprenderá, no faltan consecuencias extremadamente negativas a la potencial plasmación de este escenario, con singular relevancia en las de carácter económico ${ }^{25}$. Lógicamente, el diagnóstico del pulso vital del

${ }^{23}$ Cfr. Echevarkía Petit, J. L., «Seguridad jurídica y proliferación legislativa» en Diario La Ley, $\mathrm{n}^{\mathrm{o}}$ 7332, de 1 de febrero de 2010. Como indica Rodríguez-Arana MuÑoz, J., «Principio de seguridad jurídica y técnica normativa» en Repertorio Aranzadi del Tribunal Constitucional, $\mathrm{n}^{\circ}$ 4, Ob. Cit., «hemos de mencionar el deterioro existente en lo que a la ley se refiere (...) Hoy en día el Parlamento ya no conoce de la expresión de la voluntad general sino, más bien, de regulaciones pormenorizadas y detalladas de materias que deberían ser competencia de la normación administrativa pero que vienen a la sede de la soberanía popular sencillamente porque así tales disposiciones gozan de una mayor resistencia jurídica que si fueran objeto de la potestad reglamentaria (...) Junto al proceso de administrativización de la ley (...) nos encontramos con una creciente tendencia (...) de la reglamentación independiente, fenómeno excepcional que se convierte en ordinario cuando el Parlamento se convierte en un poder subordinado al Ejecutivo».

${ }^{24}$ Con mayor detalle, Pulido Quecedo, M: « La doctrina del TS sobre las leyes de acompañamiento a la luz del principio de seguridad jurídica» en Repertorio Aranzadi del Tribunal Constitucional, $\mathrm{n}^{\circ}$ 21, Pamplona, 2012.

${ }_{25}$ Conforme anota PASTOR PrIETO, «las economías necesitan marcos politicos y juridicos que sean estables y previsibles, que se adapten con facilidad y rapidez a los cambios de la economía y la sociedad. La seguridad jurídica exige que el sistema jurídico-politico posea ciertas características, cuya ausencia nos lleva a identificar otras tantas fuentes de inseguridad. La inseguridad proviene de: (1) Unas normas originarias y derivadas (reglamentos, órdenes, circulares) excesivamente abiertas, ambiguas e indeterminadas, complejas y cambiantes con excesiva frecuencia que dificultan el conocimiento y certeza del Derecho positivo (2) Una actuación administrativa gravosa, lenta e incierta, con excesiva discrecionalidad (3) Una Justicia lenta, costosa, incierta e ineficaz, sin líneas jurisprudenciales claras (4) La falta de seguridad que padecen las personas y empresas como consecuencia de la criminalidad (5) Un sistema político excesivamente inestable 
principio de seguridad jurídica no puede resultar más preocupante, en estado de coma profundo: en absoluto es viable defender con solvencia la pervivencia plena de la predictibilidad, la cognoscibilidad normativa, la expectativa fundada de que el Juez resolverá la controversia nacida en un sentido razonablemente previsto de antemano.

Efectivamente, si recordamos la definición aportada por la Memoria 1992 del Consejo de Estado en la que más arriba nos deteníamos, podremos contrastar que no se cumplen ni remotamente los parámetros que allí se trazaban -infra-. Nos colocamos en una situación real en la que es imposible tener un conocimiento inequívoco de las normas que se hallan en vigor, en la que prima una calidad técnico-legislativa intachablemente cuestionable, presidida por la desnaturalización de la concepción de la ley al primar leyes omnibus, leyes chatarra, leges repetitae, aderezadas por un exceso reglamentario... Toda una antítesis de una efectiva mínima estabilidad que lleva a contrastar la situación de extrema emergencia en la que el Ordenamiento jurídico se ha ubicado, donde el principio de seguridad jurídica, que sirve como termómetro con el que medir su frescura, está siendo atacado «gravemente en su línea de flotación, que puede llevarla directamente hasta la más negra sima de la arbitrariedad $»^{26}$.

e imprevisible, falto de transparencia y participación. Su ausencia implica y se traduce en incertidumbre, imprevisibilidad e inestabilidad, en un riesgo extra para el país o la actividad que la padecen, y con frecuencia acarrea la imposición de una prima de riesgo a las inversiones en aquellos lugares donde la inseguridad es mayor. Eleva costes y precios, encarece y reduce el crédito comercial y financiero, inhibe la contratación y los proyectos; desanima la innovación y la inversión y hace que disminuya la producción. En ocasiones fomenta la aparición de buscadores de rentas e incentiva la presencia de los grupos de interés (...) Las sociedades y los mercados tratan de paliar los problemas de la inseguridad jurídica mediante diversos mecanismos. Entre los más importantes están la actuación de notarios y la fiabilidad de los registros, la intervención de los reguladores sectoriales (en energía, comunicaciones, mercado de valores, sistema financiero, etc.), el asesoramiento jurídico de los abogados ex ante o previo a la realización de operaciones, el gasto público, la adopción de medidas de seguridad, la aprobación de normas y la mejora de la Justicia (...) El sistema jurídico -y el judicial como parte de él-afecta a variables que son fundamentales para el crecimiento económico. Incide de manera directa en los costes de producción y transacción, la inversión y las mejoras tecnológicas, $y$ de forma indirecta en prácticamente todas las demás dimensiones de las que depende el crecimiento. Suministra un marco regulador, una especie de clima en el que operan, viven y crean valor personas, empresas e instituciones, y garantiza el cumplimiento de las reglas y los acuerdos que las partes contraen, asi como el respeto de los derechos y libertades, de las económicas entre otras. De esta manera proporciona un marco de estabilidad, previsibilidad y seguridad, que son dimensiones centrales en la formación de expectativas de los inversionistas», PASTOR PRIETO, S., «Justicia y Economía: panorámica, crítica e implicaciones» en Justicia y Economía, n 49, CGPJ, Escuela judicial, Madrid, 2009, págs. 92-100.

26 Pérez Ron, J. L., «La seguridad jurídica en la España actual» en Quincena Fiscal Aranzadi, n 10, Pamplona, 2012. 
Como corolario, los operadores jurídicos y todos los ciudadanos se ven sujetos al padecimiento de una estructural incertidumbre en la práctica integridad de las materias que el Ordenamiento jurídico regla, lo que deviene plenamente contrario a cualquier idea aledaña a la seguridad jurídica. Que ese desconcertante marco se agudice al albur de una crisis económica, por gigantesca que resulte, no tiene justificación habida cuenta que no sirve como excusa para enterrar un pilar básico de nuestro sistema constitucional que, más que nunca en atención precisamente a la coyuntura histórica, ha de reconocerse y respetarse con plena y reforzada pulcritud.

Como apunta GARCía DE ENTERRÍA ${ }^{27}$, «la seguridad jurídica es una exigencia social inexcusable» pero «constantemente deficiente». Esta deficiencia se ancla a lo que el autor denomina «legislación del Derecho», entendido como un proceso en que al abusarse de manera flagrante de la norma escrita por su condición de máxima garantía de la seguridad jurídica frente a otros elementos jurídicos integrantes del Derecho (cfr. art. 103.1 CE: «con sometimiento pleno a la Ley y al Derecho». Toda Ley es Derecho, pero no todo el Derecho es Ley) deviene una abrumadora amenaza de primer orden para ese principio constitucional. Subsanar esa crisis requiere, a buen seguro, un cierto desapego de esas normas irremisiblemente motorizadas y poner nuestra mirada en los principios más genéricos (seguridad jurídica incluida, que simultáneamente sería principio per se a la par que medio para orientar toda esa línea reparadora de tantos dañosos excesos legislativos). Debemos buscar refugio a esa tempestad normativa desatada al abrigo de nociones jurídicas más generales, tal vez vagas y poco precisas, pero rotundamente más sustanciales e inmutables por erigir las columnas sostenedoras del sistema jurídico en su conjunto.

Si nos resulta imposible alcanzar el conocimiento del universo jurídico que regula nuestra convivencia social, por su número y por su continuada modificabilidad, la perentoria previsibilidad normativa ha de utilizar como instrumental del que servirse el conocimiento de esos sustratos o principios generales que atraviesen trasversalmente la totalidad de lo que ha de ser un Ordenamiento jurídico, internamente pleno, único y coherente. Otra cosa es que el empuje de esa desvertebración sea tal que llegue a atomizar la unicidad estructural del Derecho, que pasa a descomponerse en trozos casi antagónicos que, a su vez, cuentan con sus particulares principios - ergo no principios en sentido propio, supra- no necesariamente armónicos con los de los restantes ${ }^{28}$.

27 García de Enterría, E., Justicia y seguridad en un mundo de leyes desbocadas, Civitas, Madrid, 1999.

28 A mayor abundamiento, Bercovitz Rodríguez-Cano, R., «No es forma de legislar» en Aranzadi Civil, n 17, Pamplona, 2002. Igualmente, Martínez Corral, J. A., «La corrección y el enjuiciamiento de las leyes errantes» en Revista Jurídica de la Comunidad Valenciana, $\mathrm{n}^{\circ} 27$, Valencia, 2008. 
Por ello, estamos ante una realidad del Derecho que lo destierra a larga distancia de cualquier atisbo de seguridad jurídica o Justicia, que obvia la protección del valor de la seguridad jurídica como presupuesto de la justicia misma del Sistema, que no quiere reconocer que sin seguridad jurídica el Sistema no es justo. Sin mesura legislativa y una mínima estabilidad no hay certidumbre en la ordenación social. La recodificación y el relanzamiento de unos principios generales del Derecho solidificados deviene perentorio para abortar haber colocado al Estado de Derecho al borde del abismo. Todas las normas han de afanarse por integrar un Ordenamiento jurídico único, continuo y abierto (unas se crean, otras se derogan, pero sin voltear el conjunto que permanece), inspirarse en la claridad (conocimiento exacto y preciso de su entrada en vigor, ámbito personal-material-territorial de aplicación y efectos jurídicos que conllevan), tener un contenido homogéneo, completo y lógico...

El principio de seguridad jurídica expresa uno de los criterios arquitecturales que toda norma debe seguir para calificarse como tal. Y sobre esta base, las normas deben integrarse entre sí armónicamente para constituir un verosímil sistema con los principios generales presentes en todo él.

\section{UN SUPUESTO CONCRETO: LA REGULACIÓN PRESENTE DE LAS TASAS JUDICIALES}

Tras esas reflexiones generales respecto a la seguridad jurídica abstractamente considerada, es momento de ejemplificar en un supuesto específico cuál es su doliente y convaleciente estado de salud actual. Nos serviremos para ello de la concreta institución tributaria (incluso ficticiamente procesal, a la luz de la regulación legislativa ahora positivamente en vigor) que suponen las tasas judiciales. A su vez, es conveniente desdoblar la argumentación a trazar, por un lado, en una referencia ubicativa de esta figura jurídica y, por otro, en el análisis de la normación que las ha venido rigiendo a través del tamiz del principio de seguridad jurídica para testar su propia viveza como tal criterio jurídico-constitucional.

\subsection{Consideración general}

En un giro copernicano, las tasas judiciales que parecían un fósil jurídico totalmente olvidado después de su supresión integral por la Ley 25/1986, de 24 de diciembre, (BOE de 31 de diciembre de 1986, n $\left.^{\circ} 313\right)$ volvieron a la vida mediante el art. 35 de la Ley 53/2002, de 30 de diciembre, de Medidas Fiscales, Administrativas y del Orden Social, $(B O E$ de 31 de diciembre de $2002, n^{\circ} 313$ ). Ciertamente, la reintroducción de esta figura tributaria fue sensiblemente mitigada, ceñida a supuestos muy específicos y con un principio inspirador inevitable: el criterio general respecto a ellas era la exención, tanto en una perspectiva subjetiva (únicamente quedaban sujetas a su pago las personas jurídicas que, además, tuviesen demostrado un nivel de facturación económica reseñable; esto es, esa obligación tributaria no afectaba ni a 
las personas físicas ni a un buen número de las personas jurídicas existentes) como objetiva (los hechos imponibles tipificados como sujetos a tasa judicial también se hallaban bastante acotados ${ }^{29}$.

A pesar de la cautela legislativa de la Norma de 2002 a la hora de reimplantar las tasas, las incertidumbres sobre su constitucionalidad se generaron de forma prácticamente inmediata. Esas dudas eran del todo lógicas, por cuanto esta figura tributaria interaccionaba $y$, en potencial condicionamiento, entorpecía el acceso al derecho fundamental a la tutela judicial efectiva consagrado por el art. 24.1 CE. A mayor abundamiento, esa interferencia se producía en distintos elementos de los que se aglomeran al cobijo del sistema complejo que vertebra a ese único derecho: el acceso a la Jurisdicción, el derecho a los recursos, la ejecución de lo juzgado, etc ${ }^{30}$. Como leemos en el ATC 197/2010, de 21 de diciembre, «la lesión en la misma exigencia legal (...) de condicionar el curso del proceso al pago del tributo (...) resulta desproporcionado con los fines recaudatorios a los que sirve el establecimiento del tributo (...) obstáculo insalvable (...) para la satisfacción del derecho a la tutela judicial efectiva».

Estas incógnitas fueron aparentemente despejadas de forma definitiva por la STC 20/2012, de 16 de febrero, quien estimó la constitucionalidad de gravar con tasas el ejercicio de la potestad jurisdiccional tal cual se implementaba por la Ley 53/2002, de 30 de diciembre, en los órdenes civil y contencioso-administrativo, indicando que «en principio no vulnera la Constitución que una norma de rango legal someta a entidades mercantiles con un elevado volumen de facturación -fundamental matiz que hemos de subrayar destacadísimamente- al pago de unas tasas que sirven para financiar los costes generados por la actividad jurisdiccional que conlleva juzgar las demandas que libremente deciden presentar ante los Tribunales del orden civil para defender sus derechos e intereses legítimos ${ }^{31}$. De todas formas, ese visto

${ }^{29}$ Cfr. Rodríguez Carbajo, J. R., «Las tasas judiciales: 1959-2012» en Diario La Ley, $\mathrm{n}^{\mathrm{o}} 7979$, de 5 de diciembre de 2012.

30 Desarrollando el contenido de este derecho fundamental, vid. GARBERí Llobregat, J., Constitución y Derecho Procesal. Los fundamentos constitucionales del Derecho Procesal, Cuadernos Civitas, Thomson Reuters, Pamplona, 2009. El autor entiende este derecho en perspectiva material como«el derecho a acceder a los Tribunales para plantearles la pretensión procesal y obtener de éstos, sin padecer estado alguno de indefensión a lo largo del proceso, una resolución, a ser posible de fondo, motivada y fundada en el derecho objetivo y en las pruebas practicadas, congruente con las peticiones esgrimidas por los litigantes, frente a la que podrán imponerse los recursos establecidos legalmente, y que, una vez alcanzada la firmeza, resultará susceptible de ejecución forzosa e inmodificable fuera de los cauces previstos por el Ordenamiento» (pág. 130). También DíEz-PicAzo, L. Ma., Sistema de derechos fundamentales, Thomson-Civitas, Madrid, 2003, págs. 363-390. Lógicamente, el radio de acción del precepto ha sido configurado asimismo por la abundantísima doctrina al respecto del TC. Solamente compete en este trabajo dejar apuntado este tema.

31 Vid. Loredo Colunga, M., «Las tasas judiciales: una controvertida alternativa de financiación de la Justicia» en Indret-Revista para el Análisis del Derecho, n² 270, Bar- 
bueno tampoco se planteaba incondicionalmente, pues cabría la posibilidad de que hubiera inconstitucionalidad de la figura si con ella «se demostrase que la cuantía de las tasas establecidas (...) son tan elevadas que impiden en la práctica el acceso a la Jurisdicción o lo obstaculizan en un caso concreto en términos irrazonables". Como realza Magro Servet, "esta viabilidad constitucional dependerá de la consideración acerca del carácter excesivo o no de la tasa impuesta (...) Si la suma de la tasa fija y la (...) variable (...) entra o no en el exceso que cuestiona el $\mathrm{TC} \gg{ }^{32}$. Concuerda con ese parecer Gimeno SEndRa, al indicar que «la cuota tributaria de la vigente Ley de Tasas (...) puede resultar desproporcionada al patrimonio de su sujeto pasivo y erigirse en un obstáculo para el ejercicio del derecho fundamental a la tutela judicial efectiva, tal y como nuestro Tribunal Constitucional pudo declarar en su doctrina sobre la fianza del acusador particular (SSTC 62/1983, de 11 de julio; 113/1984, de 29 de noviembre; 147/1985, de 29 de octubre; 21/1987, de 19 de febrero y 79/1999, de 26 de abril), que mutatis mutandis podría ser también aquí reclamada» ${ }^{33}$.

Así, el TC entroncaba de lleno con la jurisprudencia trazada respecto a este particular por el Tribunal Europeo de Derechos Humanos (TEDH), que reiteradamente ha proclamado que las tasas judiciales, aun válidas in abstracto, no deben ser excesivas a la luz de las circunstancias propias de cada uno de los casos en los que se presenten, de tal forma que lleguen a impedir la satisfacción del contenido esencial (e indisponible a este factor tributario) del derecho de efectivo acceso a la Justicia (v. gr. SSTEDH de 26 de julio de 2005 -Kniat c. Polonia-, 28 de noviembre de 2006 -Apostol c. Georgia-, ó 9 de diciembre de 2010 -Urbanek c. Austria-).

En una interpretación muy extensiva, ciertamente autocomplaciente, sesgada e interesada del nihil obstat del TC que se reducía a los presupuestos normados por la Ley 53/2002, y contra la opinión de sendos informes emitidos tanto por el Consejo de Estado como por el Consejo General del Poder Judicial (que, respectivamente, hablaban de «magnitud exorbitante» y de un «incremento (...) en términos generales excesivo»), se promulgó la Ley 10/2012, de 20 de noviembre, por la que se regulan determinadas tasas en el ámbito de la Administración de Justicia y del Instituto Nacional de Toxicología y Ciencias Forenses (LTJ, en adelante; $B O E$ de 21 de noviembre de 2012, n $^{\circ} 280$ ).

Evidentemente, no se puede esconder que en el empeño legislativo, por muchas excusas y disfraces que se arguyan, pesa definitivamente la horrible coyuntura económica que se atraviesa, en la que al Estado le urge perentoria-

celona, 2005.

32 Magro Servet, V., «Análisis sobre la viabilidad constitucional de la Ley 10/2012, de 20 de noviembre, de tasas judiciales» en Diario La Ley, $\mathrm{n}^{\circ} 7197$, de 23 de noviembre de 2012 .

33 Gimeno Sendra, V., «La Ley de tasas en el orden procesal civil» en Diario La Ley, n ${ }^{\circ} 8037$, de 6 de marzo de 2013. 
mente recaudar fondos públicos de todas las maneras posibles para sofocar la hercúlea deuda acumulada. Bien es cierto que habría que matizar que no todo es ni ha de ser Economía, y desde luego el plantel de derechos fundamentales no debería quedar interferido por puros avatares financieros, por graves o desconocidos en precedencia histórica que resulten. No en vano la distinción intraestatal entre un momento propiamente político (en que se engarza el ciclo económico, presidido por la variabilidad casi estructural) y otro jurídico (mucho mas estable y anhelablemente ajeno a esos vaivenes por erigir un sustrato basal de la organización estatal), debe permanecer a pleno rendimiento como manifestación de la perdurabilidad del Estado.

A pesar de esa consideración, transida por un empuje recaudatorio voraz imposible de difuminar por muchos sofismas y bonitas declaraciones legislativas que le acompañen, la LTJ ejecutó a un drástico incremento de la figura de las tasas judiciales, subjetivamente (al afectar por igual a personas físicas y jurídicas, como regla general, con algunas puntuales exenciones, ergo volteando los criterios genéricos que inspiraban las tasas reguladas en la Ley 53/2002), objetivamente (el elenco de jalones o hitos procesales seleccionados como hechos imponibles de la tasa se multiplicó en progresión geométrica) y cuantitativamente (las sumas a recaudar en concepto de tasa judicial no son nada desdeñables, tanto en su parte fija $-\mathrm{p}$. ej. en el orden civil, $150 €$ en los juicios verbal y cambiario, $300 €$ en juicios ordinarios, 100 $€$ en los procedimientos monitorio, monitorio europeo y demanda incidental concursal, $200 €$ en ejecuciones extrajudiciales y oposición a la ejecución de títulos judiciales, $200 €$ para los concursos necesarios, $800 €$ en la interposición de un recurso de apelación y $1.200 €$ si los recursos a entablar fueran el de casación o el extraordinario por infracción procesal, art. 7.1 LTJ- cuanto en la parte variable a añadir como porcentaje del principal reclamado en el procedimiento del que se tratara -cfr. art. 7.2 LTJ-).

A mayor abundamiento, el legislador procedió a considerarlas como un requisito procesal y no tributario. La fictio iuris introducida resulta realmente inverosímil, pues un tributo nada tiene de procesal incluso en una simple perspectiva estrictamente sistemática (la LTJ no se inserta en las leyes de ritos, como es natural). Aun con esa convicción, la realidad legal es la que es y, a partir de ella, el legislador le apareja consecuencias igualmente contundentes que, de paso, extirpan ciertas dudas y prácticas que los órganos jurisdiccionales venían manteniendo bajo el imperio de la ahora derogada regulación de las tasas por la Ley 53/2002 (infra). En efecto, como nos anuncia el Preámbulo de la LTJ y realzan López JARA y Flores RodrígueZ, «la Ley (...) configura la nueva tasa no sólo como una obligación tributaria, sino también como un requisito procesal con las importantes conclusiones de producir la preclusión de los actos procesales gravados con la tasa e, inclu- 
so, la terminación anticipada del proceso sin una resolución de fondo» ${ }^{34}$. En consonancia con esa locución, dispone el art. 8 LTJ que, caso de no aportarse con el escrito seleccionado por el listado tipificado por art. 5 LTJ como hecho imponible de la tasa justificante de haberla satisfecho, el Secretario judicial «requerirá al sujeto pasivo para que lo aporte, no dando curso al escrito hasta que tal omisión fuera subsanada» en un plazo de diez días. De no cumplirse en el sentido ordenado esa subsanación, no se impedirá la aplicación de los plazos prevenidos en la legislación procesal, de tal forma que se dará lugar a la preclusión del acto procesal en liza y a la subsiguiente continuación o finalización del proceso sin obtener una resolución de fondo sobre la cuestión litigiosa suscitada.

Ya no cabe duda: queda eliminada la tentación de archivar provisionalmente el curso procesal hasta que se demuestre la pobreza habilitante de justicia gratuita del obligado tributario, o esperar a que satisfaga ese tributo aunque sea extemporáneamente siempre que no caduque la instancia... en aras de la conservación del vigor del superior derecho fundamental del art. 24.1 CE. Ahora, la LTJ pauta tajante que en caso de no abono de la correlativa tasa tras el requerimiento de subsanación formulado en resolución del Secretario judicial, el proceso no arrancará o, en su caso, no proseguirá. El archivo es la consecuencia del impago de la tasa. El derecho del art. 24.1 CE queda absolutamente al albur de un requisito procesalizado pero verazmente administrativo/tributario.

La contestación a esta regulación de la LTJ fue estruendosa e inusualmente unívoca, tanto de diferentes sectores sociales como, especialmente, de los dispares operadores jurídicos. Además de la consideración de ese ataque genérico al complejo jurídico que reside en el art. 24.1 CE, también se achacaron a la novedosa y expansiva regulación de las tasas judiciales defectos de técnica legislativa (v. $g r$., sin ir más lejos, la inicial elusión de mencionar el plazo en que debía subsanarse ese defecto de falta de acompañamiento de justificante de pago de la tasa una vez apreciado por el Secretario judicial).

De todos ellos, nos interesa reflexionar con más detenimiento en el fallo que supone que, pese a hallarse formalmente en vigor, la LTJ devino materialmente inaplicable. Así es, dado que la realización de los hechos imponibles referidos por el art. 5 LTJ aparejaba la necesidad de adjuntar a los correspondientes escritos justificantes de pago de abono de la tasa, se convertía en un aspecto necesario la aprobación de los modelos de autoliquidación en que pudiera plasmarse la cumplimentación de ese requisito formalmente procesalizado. Como indica el art. 9 LTJ, por Orden del Ministerio de Hacienda y Administraciones Públicas se regularían los procedimientos y modelos de

${ }^{34}$ López JARA, M. y Flores Rodríguez, J., «La tasa judicial para el ejercicio de la potestad jurisdiccional en los órdenes civil, contencioso-administrativo y social. Comentarios a la Ley 10/2012, de 20 de noviembre» en Diario La Ley, n 7988, de 20 de diciembre de 2012. 
autoliquidación de la tasa. Y este aspecto no se produjo hasta la entrada en vigor de la Orden HAP 2662/2012, de 13 de diciembre, por la que se aprueba el modelo 696 de autoliquidación, y el modelo 695 de solicitud de devolución por solución extrajudicial del litigio y por acumulación de procesos, de la tasa por el ejercicio de la potestad jurisdiccional en los órdenes civil, contencioso-administrativo y social y se determinan el lugar, forma, plazos y los procedimientos de presentación (OHT, en adelante).

He aquí el desastre técnico-legislativo anunciado. La LTJ se publica en el BOE de 21 de noviembre de 2012, disponiendo su Disposición final séptima que su entrada en vigor se produciría al día siguiente al de su publicación. Por su parte, la OHT se publica en el BOE el 15 de diciembre de 2012, entrando en vigor el día 17 de diciembre de 2012, aplicándose a los hechos imponibles que tengan lugar a partir de la entrada en vigor de la misma (Disposición final segunda). De esa manera, nos topamos con que desde el 22 de noviembre de 2012 hasta el 17 de diciembre de ese año contábamos con una Ley formalmente en vigor pero inaplicable, luego materialmente no vigente. De paso, resulta que una norma legal depende de una norma reglamentaria para que sea realmente efectiva. ¿No podía el legislador prever algo tan sencillo como una vacatio legis mayor para que no se produjera este desfase? $?^{35}$

Peor todavía es la solución que se arbitra para frenar el formal vigor de la LTJ en la práctica. Un puro artefacto administrativo, desde luego ayuno de cualquier consideración de fuente del Derecho y, mucho menos, incapaz de causar cualquier repercusión en el ámbito procesal a la vista del rigurosísimo principio de legalidad que prima y preside majestuoso este sector del Derecho (sin más, art. 1 de la Ley de Enjuiciamiento Civil, LEC, BOE de 8 de enero de $\left.2000, \mathrm{n}^{0} 7\right)^{36}$, es quien se apresta a dejar inaplicable la LTJ en ese intervalo cronológico. Así es, la Instrucción 5/2012, de 21 de noviembre, de la Secretaría General de la Administración de Justicia, corona del jerarquiza-

35 Algunos autores niegan la mayor. Concluye GutiérRez-Alviz ConRadi que «una norma regulada esencialmente por una norma con rango de ley no puede justificar en modo alguno un vacio tributario (...) No es factible que se dejen de exigir el pago de tasas simplemente con el argumento meramente formal de la inexistencia de los modelos de autoliquidación en la fecha de entrada en vigor de la ley (...) En la medida en que tal Orden Ministerial establece la entrada en vigor de las tasas el 17 de diciembre de 2012, sin habilitación especial alguna por la citada Ley 10/2012 y en contra de lo establecido por la misma en forma terminante sobre la entrada en vigor el 22 de noviembre, pudiere en ese concreto pronunciamiento entrañar una disposición nula de pleno derecho, por quebrantar el principio de reserva de ley y jerarquía normativa contemplado en el art. $9.3 \mathrm{CE}$, con las consecuencias de nulidad radical (...) sin que una Orden Ministerial (...) haya quedado expresamente habilitada para la fijación de la entrada en vigor de la ley», Gutiérrez-Alviz ConRAdi, F., «Las nuevas tasas judiciales: ¿Qué pasa desde el 22 de noviembre hasta el 17 de diciembre?» en Diario La Ley, n 8026, de 19 de febrero de 2013.

${ }^{36}$ Para mayor concreción sobre este espinoso particular, nos remitimos a nuestro trabajo«Perspectivas de futuro del Derecho Procesal ante el conjunto de reformas que ahora atraviesa: ¿un nuevo (e inaceptable) sistema de fuentes?» en Revista CEF Legal, Madrid, mayo de 2012. 
do Cuerpo de Secretarios judiciales (art. 452.1 de la Ley Orgánica del Poder Judicial, LOPJ, reformada por la Ley Orgánica 19/2003, de 23 de diciembre, $B O E$ de 26 de diciembre de 2003, no 309 ) pero resueltamente incrustada en la estructura del Ministerio de Justicia, luego órgano ejecutivo-gubernativo e indudablemente político ${ }^{37}$, dispone con total coactividad que «hasta tanto no se produzca la publicación en el Boletín Oficial del Estado de la Orden Ministerial a la que se refiere el artículo 9.2 de la Ley 10/2012, de 20 de noviembre (...) los Secretarios judiciales de todo el territorio nacional no exigirán en ningún caso la presentación del justificante de autoliquidación de la tasa para dar curso a los escritos procesales que se presenten».

El parche legislativo es simple aunque burdo. Ya que el encargado de controlar la recaudación de la tasa es el Secretario judicial, sobre el que pesa su condición de funcionario netamente administrativo por encima de su cualificación jurídico-procesal a la vista del tenor conjuntado de los arts. 440 y 463.1 LOPJ, reposando orgánicamente sobre los principios de unidad de actuación y dependencia jerárquica (art. 452.1 LOPJ, supra), se hace que su cúspide gubernativa, mediante un típico instrumento administrativo de ordenación doméstica (recordemos el art. 21.1 de la Ley 30/1992, de 26 de noviembre, del Régimen jurídico de las Administraciones Públicas y el Procedimiento Administrativo Común, BOE de 27 de noviembre de 1992, n 311 , a cuya letra las instrucciones sirven para «dirigir las actividades de sus órganos jeráquicamente dependientes») $)^{38}$, vinculando a sus subordinados, haga inaplicable la LTJ no sólo internamente en ese Cuerpo de funcionarios, sino a todos los niveles. Una norma jurídica queda suspendida en su virtualidad por un instrumento intraadministrativo que bajo ningún concepto tiene legitimidad alguna para operar así. Insistimos, la técnica legislativa empleada se califica por sí misma y pone un buen ejemplo del nulo cuidado cualitativo que el legislador presta al producto que tiene el monopolio de confeccionar. Además, se comprenderá que se obvia totalmente el imperativo mandato de sujeción a la ley que impone el art. 9.1 CE.

Consciente de todos estos aspectos, y muy probablemente reconociendo indirectamente la extralimitada normación implantada, el atribulado e hiperactivo legislador, estimando nada menos que la concurrencia de la «extraordinaria y urgente necesidad» exigida por el art. $86 \mathrm{CE}$ para permitir activar esta vía jurídica, promulgó el Real Decreto-Ley 3/2013, de 22 de febrero, por el que se modifica el régimen de las tasas en el ámbito de la Administración de Justicia y el sistema de asistencia jurídica gratuita (DLT, en lo sucesivo,

${ }^{37}$ «A la vista de las funciones que tiene asignadas la Secretaría General de la Administración de Justicia (...) no se trata de un mero órgano de gestión sino que tiene naturaleza política, atendida la posición que ocupa en la estructura organizativa del Ministerio de Justicia», STS 37/2012, de 23 de enero de 2012.

${ }^{38}$ A mayor abundamiento, nuestro estudio «Problemas dimanantes de la reforma procesal de 2009: A propósito de los recursos contra los recursos de los Secretarios judiciales» en Actualidad Civil, n 2, Ed. La Ley, Madrid, 2011. 
$B O E$ de 23 de febrero de 2013, $\mathrm{n}^{\circ}$ 47). Su Exposición de Motivos reseñaba los extremos sobre los que se pretendía operar esas reformas. Concretamente expresa que, aun siguiendo considerando plenamente válido que las tasas judiciales supongan un instrumento adecuado e inocuo para los derechos subjetivos, podría haber algún caso puntual e individualizado en el que su cuantía resultara excesiva, por lo que mediante el DLT se propone evitar esas concretas consecuencias.

Ahora bien, lo verdaderamente significativo a nuestro juicio radica en que se proclama que la filosofía sustentadora de la LTJ permanece intacta. Por eso, las reparaciones que se implementan son puramente cosméticas, estéticas, superficiales, tan acotadas que apenas se notan en la generalidad del sistema pergeñado por la LTJ (p. ej. que se limite la tasa en el orden contencioso-administrativo cuando el recurso se interponga contra resoluciones sancionadoras impidiendo que la tasa supere el 50\% de su importe, limitaciones -que no exclusiones- en los casos de personas naturales en la suma que configura la parte variable de la tasa...).

Efectivamente, el legislador no atajó los males que la LTJ engendró, al permanecer incólumes aspectos como el tramo fijo de la cuota tributaria, la clara desconexión de ese monto respecto al coste del servicio que teóricamente se brinda, o la extensión de la tasa a las personas físicas. De ahí que, particularmente, estimemos que los retoques efectuados en la LTJ por el DLT simplemente suponen una operación de maquillaje legislativo que, a la sazón, ni siquiera obtiene los resultados estéticos legislativamente perseguidos. El espíritu de la LTJ se mantiene, y los males apegados a las tasas judiciales, muy singularmente su riesgo de inconstitucionalidad primordialmente sustentado sobre la excesiva cuantía de las mismas, también. Posiblemente el eje de la cuestión no se apoye ya sobre la constitucionalidad de las tasas judiciales estimadas por sí mismas, en cuanto institución. Pero se traslada a si son constitucionalmente admisibles en la formulación que han tomado en la LTJ.

De todas formas, nos interesa más aquí enfocar el asunto hacia el rumbo que se ha trazado con este trabajo. Y así, contrastamos que, en el colmo de la displicencia legislativa, ha vuelto a suceder algo similar a lo que había acaecido al entrar en vigor la LTJ: el DLT también ha resultado materialmente inaplicable pese a hallarse vigente de manera formal. Efectivamente, si reproducimos el tenor de su Disposición final séptima nos encontramos literalmente con esta redacción: «Este real decreto-ley entrará en vigor el día siguiente al de su publicación en el Boletín Oficial del Estado. No obstante lo anterior, las tasas por el ejercicio de la potestad jurisdiccional que hubieran de liquidarse por personas físicas y por todos los sujetos pasivos en el caso de la presentación de los recursos contencioso-administrativos a que se refieren los números cuatro y seis del artículo 1 en el período comprendido entre el día siguiente a la publicación de este decreto-ley hasta la entrada en vigor de la Orden del Ministro de Hacienda y Administraciones Públicas por la que se adapte el modelo 696 de autoliquidación y el modelo 695 de solicitud de de- 
volución por solución extrajudicial del litigio y por acumulación de procesos, de la tasa por el ejercicio de la potestad jurisdiccional en los órdenes civil, contencioso-administrativo y social, se liquidarán a partir de esta última fecha en el plazo de quince días hábiles, quedando en suspenso los procesos en el estado en que se encuentren. Si no se efectuara dicha liquidación por los sujetos pasivos, el Secretario judicial hará el requerimiento a que se refiere el apartado 2 del artículo 8 de la Ley 10/2012, de 20 de noviembre».

Entonces, tenemos una norma de rango legal en vigor pero su aplicación efectiva precisa de un desarrollo reglamentario que no existe al tiempo de su promulgación, lo que convierte en imposible esa realización plena de su norma superior. En este caso, se perfila ligeramente la situación de pleno desconocimiento que sí se provocaba a la puesta en vigor de la LTJ, por cuanto se regula expresamente que la aplicación del DLT se producirá de modo retrasado, en una suerte de pendencia o condicionante suspensivo. Las tasas se devengan igual durante ese tiempo de vacancia entre la entrada en vigor nominal del DLT, mas su exigible efectividad depende de la existencia de una nueva norma reglamentaria apegada a sus postulados que habilite retroactivamente su recaudación con el tope cronológico de la entrada en vigor del DLT. Para cerrar esa regulación transitoria que, en realidad, el DLT efectúa para cuidarse de evitar vacíos o dudas ante la ausencia a su ganancia de exigibilidad de un desarrollo reglamentario absolutamente imprescindible, se resuelve la suspensión de la tramitación de los procesos afectados en el estado en que se encuentren, lo que ratifica cómo un requisito tributario pasa a integrarse en la estricta procesalidad o procedibilidad. De todos modos, aunque se instaure una previsión que cubra las dudas que pueda generar la inexistencia acompasada de una precisa normativa reglamentaria de desarrollo, creemos que, dejando aparte ese detalle conformante de una disposición eminentemente transitoria, afrontamos un marco similar al relatado respecto a la LTJ: una norma legal formalmente en vigor no puede aplicarse materialmente, por lo que esa aplicabilidad real y efectiva queda diferida a expensas de la norma reglamentaria.

Ha de concluirse que, pese a toda la compulsión legislativa, nada ha cambiado de manera sustancial. De ahí que conjuntemos hiperactividad normativa, extremada mala técnica y, como colofón, modificaciones ciertamente inútiles y vacuas. Nada menos que se gestan cuatro normas sobre la misma materia en escasos cuatro meses. El summum de la mediocridad legislativa.

\subsection{La regulación de las tasas judiciales desde el principio de seguridad jurídica}

Apuntábamos antes el que ha de entenderse como contenido constitucionalizado del principio de seguridad jurídica. Igualmente, se ha recorrido el tormentoso proceder legislativo que en cuestión de unas semanas ha ido experimentando la regulación de unas relanzadas tasas judiciales. Corresponde entonces encajar esa normación en los postulados propios del principio de 
seguridad jurídica prevenido por el art. 9.3 CE y analizar el resultado que se produce.

De esa conjunción se deduce un luminoso y esclarecedor ejemplo de la quiebra del principio constitucional de seguridad jurídica que de manera reiterada se constata en estos tiempos. Desgranemos cada uno de los sectores que más arriba señalábamos que ese criterio comprendía en su seno:

a) La cognoscibilidad de la normativa vigente en materia de tasas queda formalmente asegurada. Como no puede ser de otro modo, toda ella se ha ido publicando de manera oficial en el correlativo diario, el BOE. Ahora bien, un conocimiento material, pacífico, incontrovertido de esas normas posiblemente ya no sea tan diáfano. La relativa oscuridad que rodea a todo ese conjunto normativo, indirectamente reconocida por el legislador desde el momento en que procede a reformar el inicialmente introducido por un procedimiento legislativo reservado a supuestos de extraordinaria y urgente necesidad, y la ausencia de complitud de la norma legal que se ve forzosamente precipitada a depender de un desarrollo reglamentario, corroboran en nuestra opinión semejante afirmación. Añádase la articulación de prolija y densa normativa transitoria y reforzaremos este argumento. Por ende, habría que practicar alguna modulación a una cristalina cognoscibilidad de la normativa señalada.

b) Algo similar se puede concluir desde el prisma de los estándares técnico-jurídicos seguidos en la elaboración de estos productos legislativos. Obviamente, no puede ser de otra manera, se han proseguido los itinerarios prefijados de iure para la formulación de esas normas (sin perjuicio de los informes - preceptivos mas no vinculantes- negativos que las antecedieron). Ahora bien, la técnica legislativa seguida es intrínsecamente defectuosa desde el justo instante en que se precipita con una inusitada aceleración, se dispersa en cuatro normas distintas aun en necesaria comunión ratione materiae en cuestión de semanas y se reenvía de unas a otras pretiriendo el imperio de condicionantes previos como el principio de legalidad o la jerarquía normativa, reflejando un sensible grado de titubeos a la hora de legislar.

c) Aplastantemente, la mínima estabilidad en la permanencia de las normas elaboradas y puestas en vigor no existe. Que en cuatro meses se hayan efectuado dos normaciones legales que, a su vez, precisan materialmente de soluciones reglamentarias que, entre tanto se promulgan, exigen unas soluciones de imaginativa ingeniería legislativa supone la antítesis de cualquier sosiego normativo en óptica cronológica y ataca de manera frontal este enfoque propio del principio constitucional de seguridad jurídica sin que semejante evidencia precise de mayores justificaciones.

d) La necesaria superioridad de los grandes principios y valores jurídicos mayormente constitucionalizados que apuntalan la existencia y permanencia del Ordenamiento jurídico, que actúan como arquitrabes que impiden su colapso, queda claramente en entredicho. Hemos repasado cómo con la regulación en materia de tasas judiciales se interfiere negativamente 
con el principio de seguridad jurídica a quien se dedican estas reflexiones, pero también de refilón se infiere que se inflige padecimiento a otros como el principio de legalidad (lesionado cuando un instrumento administrativo como una instrucción pone de manifiesto una suspensión en la aplicación de una norma legal pese a que ella misma proclame que se halla en vigor) o la jerarquía normativa (la plenitud de una ley formal no debería quedar al albur de normativa reglamentaria). El elenco del art. 9.1 CE no parece salir especialmente bien parado de su cohonestación con la regulación de las tasas judiciales pese a que, naturalmente, deba imponerse sobre ella. Naciendo de estas premisas, mal va a articularse un racional conjunto normativo ya no sólo a los principios constitucionales, sino también a la tabla axiológica que inspira a nuestro Sistema jurídico.

\section{IDEA FINAL}

La idea final que con tristeza hay que realzar estriba, a nuestro entender, en focalizar la mediocridad legislativa que padecemos. El legislador que sufrimos en los últimos años tiende acuciantemente a agudizar un alarmante ritmo de ocurrencias normativizadas que simplemente exteriorizan sin disimulo la absoluta carencia de criterio, la ausencia de unas prioridades clarificadas a normar, el cortoplacismo del ahora mismo. Lo que prima son bandazos, vaivenes, ensayos a costa de las pretensiones y derechos de los demás... Qué sensación de credibilidad, qué certeza se puede dar a nuestra sociedad, qué imagen de coherencia y seriedad puede ofrecerse a inversores extranjeros, a los mercados financieros, a las tan necesarias instancias internacionales... con una concreta regulación en materia de tasas judiciales que, además de ser holgadamente abigarrada y confusa per se, se intenta disfrazar en la consecución de unos objetivos que no le son propios $\mathrm{y}$, a mayor abundamiento, ha sufrido dos regulaciones (cuatro si consideramos también la precisa normación reglamentaria sin cuyo concurso no puede ni siquiera aplicarse materialmente) en cuestión de semanas, añadiendo la casi estructuralidad de la normativa transitoria. ¿De veras podemos afirmar con mínima solidez que hay una inquebrantable seguridad jurídica en el país? Desde luego, el ejemplo seleccionado no parece apuntar precisamente en esa dirección. Seamos conscientes de que seguramente la idealizada perfección de un conjunto tan vasto como el Ordenamiento jurídico se ha convertido en un imposible. Pero ello no justifica el insufrible nivel de deterioro al que nos exponemos ahora mismo, que volatiliza cualquier atisbo de seguridad jurídica.

La conclusión obtenida de ese contraste de un aspecto particular con un principio general tiene otras derivadas más graves aún. La seguridad jurídica, su lamentable estado de salud, sirve de buen indicador de la calidad de nuestro Estado de Derecho. La sujeción del obrar y actividad estatal al imperio del Derecho a buen seguro flaqueará, pues ni siquiera se sabrá certeramente a qué atenerse con mínima estabilidad. Más bien se vive en una compleja interinidad que, a la sazón, demasiadas veces parece que intenta sortear su 
sometimiento a los máximos postulados constitucionales. La seguridad jurídica renquea, el Estado de Derecho probablemente también... ¿no lo hace la Constitución?, ¿no está siendo una víctima más de todo el desaguisado en el que navegamos como sociedad, en una crisis que cada día parece más sistémica? Debemos reflexionar e inducir conclusiones más generales desde el análisis de elementos concretos como el propuesto. Y tenemos que corregir una peligrosa deriva en la que nos precipitamos. Va en ello los derechos de todos, que ya no quedan cubiertos por su mera proclamación formal. Levantemos los velos...

RESUMEN: La seguridad juridica es un principio del Derecho totalmente constitucionalizado, y porta un contenido propio que, a la vez, se proyecta sobre todo el Ordenamiento jurídico para poder cualificarlo como tal, sirviendo de criterio indicativo de la veraz viveza del Estado de Derecho. No es desconocido que se ha venido contrastando desde hace años su debilitamiento material, al margen de su proclamación formal. Los últimos tiempos han incrementado exponencialmente ese padecimiento constitucional. En este trabajo se propone contrastar esa situación sirviéndonos de un ejemplo de actualidad: las relanzadas tasas judiciales y su encaje en el ámbito propio del referido principio constitucional. Se intentará demostrar que el resultado de ese ejercicio no será muy positivo.

Palabras ClaVE: Constitución, tasas, seguridad, debilitamiento, ordenamiento.

TITLE: Effects caused by a compulsive legislator in the juridical safety. The example of the amplified judicial taxes.

ABSTRACT: The constitutionalized juridical safety carries an own content that, simultaneously, projects especially the juridical Order to be able to qualify it, as such serving as indicative criterion of the veracious quickness of the Constitutional state. For time, it has come confirming his material weakening, although his formal proclamation Last times have increased this constitutional suffering. In this work we propose the confirmation of this situation using an example of current importance: the new judicial taxes and their lace in the own area of the above-mentioned constitutional content. We will try to test that the result of this exercise will not be very positive.

KEYWORDS: Constitution, taxes, safety, weakening, order.

Recibido: 18.03.2013

Aceptado: 02.09.2013 